\title{
Measuring the economic impact of Research Joint Ventures supported by the EU Framework Programme
}

\author{
Ascensión Barajas $^{\mathrm{a}^{*}}$, Elena Huergo ${ }^{\mathrm{b}}$ and Lourdes Moreno ${ }^{\mathrm{b} * *}$ \\ ${ }^{\mathrm{a}}$ Department of Impact Analysis, CDTI, Madrid, Spain; \\ ${ }^{\mathrm{b}}$ GRIPICO - Department of Economic Analysis, Universidad Complutense de Madrid, Spain
}

May 2011

\begin{abstract}
The objective of this paper is to analyse the effects of international R\&D cooperation on firms' economic performance. Our approach, based on a complete data set with information about Spanish participants in research joint ventures supported by the EU Framework Programme during the period 1995-2005, establishes a recursive model structure to capture the relationship between $R \& D$ cooperation, knowledge generation and economic results, which are measured by labour productivity. In the analysis we take into account that the participation in this specific type of cooperative projects implies a selection process that includes both the self-selection by participants to join the consortia and the selection of projects by the European Commission to award the public aid. Empirical analysis has confirmed that: (1) R\&D cooperation has a positive impact on the technological capacity of firms, captured through intangible fixed assets and (2) the technological capacity of firms is positively related to their productivity.
\end{abstract}

Keywords: international R\&D cooperation, Framework Programme, impact assessment

J.E.L. Classification: H81, L2, O3

\footnotetext{
The authors thank Isabel Busom, Luis Corchón, Pierre Mohnen and the audiences at the ASIGO Conference (Nuremberg), the $36^{\text {th }}$ Conference of the EARIE (Ljubljana), the CONCORD 2010 (Sevilla), the seminar at the Departament d'Economia Aplicada of the Universitat Autònoma de Barcelona and the seminar of the CSIC Institute of Public Goods and Policies for their helpful comments. All errors are ours. This research has been partially funded by the CICYT projects SEJ2007-65520/ECON and ECO2010-18947/ECON. Elena Huergo and Lourdes Moreno also acknowledge financial support from CDTI to develop this research.
}

* CDTI (Centre for the Development of Industrial Technology). Dpto. de Estudios y Calidad. C/Cid 4, 28001 Madrid. España. E-mail: abi@,cdti.es

** Corresponding author: GRIPICO (Group for Research in Productivity, Innovation and Competition). Dpto. Fundamentos del Análisis Económico I. Facultad de CC. Económicas y Empresariales. Universidad Complutense de Madrid. Campus de Somosaguas. 28223 Madrid. España. Tel.: +34 913942408. Fax: +34 913942561. E-mail: lmoreno@ccee.ucm.es 


\section{Introduction}

The objective of this paper is to analyse the effects of R\&D cooperation, exploring the relationship between cooperation, knowledge generation and economic results. Specifically, we focus on research joint ventures (RJV) supported by the R\&D Framework Programme (FP) of the European Union and study the impact of this type of technological agreement on the labour productivity of private participants.

RJV have been defined in the literature as formal arrangements to cover non-equity agreements and organized so that partners (public or private organizations) can pool resources in order to undertake joint R\&D activities (Hagedoorn, Link and Vonortas, 2000). Consortia shaped under the FP have been considered to be a clear example of international RJV, since they involve partners from different nationalities which invest their own resources in $R \& D$ activities in order to obtain appropriable results (Caloghirou and Vonortas, 2004).

Literature concerning RJV performance remarks the complexity of this analysis, due to the multidimensional character of technological cooperation and, thus, the absence of broad accepted indicators. The choice between objective performance measures, such as profitability or growth rates, and subjective data collected form surveys, will be strongly determined by the target of the study (Veugelers, 1998; Martin, 2003). Likewise, the unit of analysis (individual partners or collective performance) will be selected according to the scope of the evaluation (Branstetter and Sakakibara, 2002).

The interest in knowing the economic effects of RJV is even more justified when cooperation is supported by public funds (Combs and Link, 2003). As for RJV supported by the FP, the great part of the research has considered individual participants as unit of analysis, although there are remarkable attempts aiming to explain how the FP contributes to build and consolidate R\&D networks within the European area (Roediger-Schluga and Barber, 2006; Breschi and Cusmano, 2006). Prior studies have followed different and complementary methodologies, pointing out the positive effect of this type of cooperative agreements on firms' technological capabilities (Tsakanikas and Caloghirou, 2004; Dekker and Kleinknecht, 2008; Polt, Vonortas and Fisher, 2008). Nevertheless, empirical evidence about the effect of the FP on firms’ economic performance is scarce (Bayona-Sáez and García-Marco, 2010). 
With the aim to enlarge this evidence, our approach elaborates on economic performance of RJV supported by the EU FP. Given the technological character of these consortia, we think that productivity can be an outstanding measure of economic results. Recent literature recognises new knowledge as an essential source of firms' productivity growth, pointing out that this growth is more related to the results of technological activities than to the inputs used in them. Specifically, Crepón, Duguet and Mairesse (1998) developed a multi-equational model (hereafter the CDM model) that explains productivity growth by technological outputs and the outputs by technological effort. Based on this research, we estimate a recursive empirical model to capture the relationships between $R \& D$ cooperation, knowledge generation and labour productivity. Under this model, we are assuming that participation in the FP would help firms to improve their technological profiles, and these new capabilities could lead to ulterior productivity increases. Thus, participation in the FP could have an indirect effect on this performance measure.

In addition, we take into account that the participation in RJV supported by the EU FP implies a process selection that includes both the self-selection by participants to join the R\&D consortia and elaborate a proposal, and the selection of projects by the European Commission to award the public aid. In fact, the main obstacles that authors must face when trying to measure the economic impact of participation in the FP are two: 1) how to avoid the self-selection effect and 2) how to join data on participation and on economic performance for a period long enough to capture the long-term effect of the FP R\&D projects.

Following Barajas and Huergo (2010), our empirical approach takes into account that cooperation in this program is the result of two decisions. First, firms have to decide whether or not they engage in the consortia. Second, the agency decides to approve or to reject the project after the evaluation. In this second stage, we are considering a selection equation in order to avoid the self-selection effect that can produce bias when the information considered refers only to firms with accepted projects. Afterwards, we analyse the effect of participating in the FP on technological and economic results.

The second obstacle has been solved by joining two complementary databases. The first one, provided by the CDTI (the public organism in charge of monitoring the participation of Spanish firms within the FP), contains much relevant information about the FP projects and the participants and allows us to discriminate between the decision to apply and the agency selec- 
tion. Additionally, we use data provided by the SABI database that consists of company accounts for over 1,000,000 Spanish firms. This allows us to build a control sample with information on economic variables. Thus, we compile homogeneous samples containing information about more than 50,000 firms and for a long-term period.

In contrast to other impact studies of the FP, the features of our database allow us to carry out the empirical analysis from a more in-depth and precise approach. Moreover, our database contains information for a period long enough to capture the long-term impact of participation in FP consortia. Thus, we consider a time lag of five years from the application year of each project. Other works are not able to establish the same time lag for all the projects or consider a short-term horizon ${ }^{1}$. Finally, previous literature does not take into account the existing differences among FP instruments. In order to guarantee the homogeneity of the sample, only Specific Targeted Research Projects (STREPs) and Integrated Projects are considered in the present paper since these participation modalities fit the RJV definition.

Following this introduction, Section 2 summarises prior literature focused on R\&D cooperation impact and, more specifically, on the FP. In Section 3, we present the database and the model used to carry out the empirical analysis contained in Section 4. Finally, in Section 5, we draw some conclusions from the results, also pointing out key policy implications.

\section{Previous empirical evidence on the impact of $R \& D$ cooperation}

Literature analysing the impact of $R \& D$ cooperation points out the obstacles to find appropriate indicators, due to the multidimensional nature of this topic and the difficulties of data collection (Veugelers, 1998). Several approaches co-exist, regarding the unit of analysis (individual participants or collective performance) and the type of measures (objective or subjective indicators) (Caloghirou, Ioannides and Vonortas, 2003). Since RJV have multiple targets, the assessment of results will be determined by the fulfilment level of partners' objectives. Empirical studies have focused, mainly, on individual participants, stressing the relevance of harmonizing methodology background with evaluation targets. Econometric analysis of R\&D

\footnotetext{
${ }^{1}$ Benfratello and Sembenelli (2002) consider a sample of firms participating during the period 1992-1994, indistinctly, and analyse their economic results for the period 1995-1996. Dekker and Kleinknecht (2008) use information for firms supported in FP4 and FP5, but they have no information about the concrete year of participation. Impact is measured considering sales of new products introduced in the market during the period 20022004 for the whole sample.
} 
outputs is recognized as one of the most appropriate method to evaluate the effectiveness of private outputs (Martin, 2003).

Theoretical foundation of impact analysis faces also the heterogeneity of models. R\&D cooperation has been explained from several conceptual perspectives. Thus, the effect of cooperation on firms' performance could be interpreted according to different theoretical assumptions (Caloghirou, Ioannides and Vonortas, 2003). Whereas industrial organisation and transaction costs theories have explained RJV from a cost-profit neoclassical model, other approaches related to strategic management stress the strategic relevance of cooperation and focus on aspects inside the firm, such as access to external knowledge, learning processes or internal absorptive capacity. From the resource-base perspective, R\&D partnerships and in-house R\&D are considered complementary strategies aiming to increase technological capacities of firms. Following this conceptual framework, many authors have built objective performance indicators related to technological capabilities (mainly from patents databases) and have concluded that $R \& D$ partnerships have the predicted positive effect on internal capacity (Mowery, Oxley and Silverman, 1998; Branstetter and Sakakibara, 2002; Scott, 2003).

With the improvement and international harmonisation of innovation statistics in the European Union (mainly throughout the Community Innovation Survey (CIS) in the 1990s), researchers were able to measure the impact of $R \& D$ cooperation on new output indicators closer to the firms' innovative activity. This source of information also allows for distinguishing different kinds of cooperation according to the type of organisation selected by the company to carry out joint R\&D projects. Researchers introduce explanatory variables capturing the type of cooperation (related to the type of partner) in empirical models, and measure their impact on some indicators of innovation output. Most of the papers find a positive relationship between cooperation with universities/research centers and innovation output measured by the volume of sales due to new products (Lööf and Heshmati, 2002; Faems, Van Looy and Debackere, 2005; Lööf and Broströn, 2008). These results corroborate the relevance of Intellectual Property Protection as explanatory variable of cooperation impact, especially when partners are universities or public institutions (Hall, Link and Scott, 2001).

Empirical research focused on economic impact of RJV has been carried out more frequently in the framework of policy assessment. The increasing amount of public funds devoted to 
R\&D consortia in the European Union and the changes in antitrust rules allowing joint ventures in US are two clear examples of this trend.

At this respect, Combs and Link (2003) analyze the economic foundation of research partnership, aiming to justify public intervention. From an exhaustive review of previous theoretical studies, they conclude that research partnerships are a socially beneficial organizational form, but they stress also that more empirical research focused on economic efficiency is needed.

One of the first studies analysing the effect of cooperation on economic results was carried out by Siebert (1996). This author uses a sample of 314 US joint research ventures registered from 1985 to 1992 in the NCRA-JRV databases (National Cooperative Research Act) and confirms that the effect of R\&D intensity on profit margin is higher for cooperating firms than for non-cooperating firms. Nevertheless, cooperation does not affect profit margin.

Using data from CIS and other objective information sources, Belderbos et al. (2004) measure the effect of different types of cooperation on Dutch firms' performance, captured by two indicators: the growth of added value per employee (as an indicator of labour productivity) and the growth of sales per employee from new-to-the-market products (as an indicator of "innovative sales productivity"). Available data for the period 1996-1998 allow them to match information on innovative activity and financial indicators for more than 2,000 enterprises. They cannot confirm that cooperation with universities has an effect on labour productivity, but instead find a significant impact on innovative sales growth. Aschhoff and Schmidt (2008) reinforce the positive relationship between cooperation with universities and the newto-the-market product innovation. In the same study, these authors also confirm the effect of cooperation in process innovation, capturing throughout this indicator the cost-reduction factor associated with collaborative R\&D.

Another remarkable attempt to demonstrate the economic effects of R\&D cooperation is the paper by Cincera et al. (2003). These authors analyse the effect of international R\&D cooperation by including not only $\mathrm{R} \& \mathrm{D}$ expenditure, but also $\mathrm{R} \& \mathrm{D}$ cooperation in a classical productive growth function. This latter indicator is a proxy of available external know-how (knowledge spillovers) and complements the internal innovation effort. Empirical results confirm the positive impact of R\&D intensity on sales growth. However, only cooperation with 
more applied objectives (with customers, suppliers or other companies) has a positive impact on sales growth.

In general, the literature confirms the existence of a positive relationship between R\&D cooperation and innovative results, but the effect on economic performance is not so evident. Taking into account different types of cooperation processes, empirical evidence seems to corroborate that the more market-oriented the cooperation is, the higher the probability of finding positive economic effects (Benfratello and Sembenelli, 2002; Cincera et al., 2003; Belderbos et al., 2004; Bayona-Sáez and García-Marco, 2010).

\subsection{The impact of cooperation taking place within the FP}

The Framework Programme (FP) is the main political instrument supporting cooperative R\&D within the European Union. It was born in 1984 with the aim of coordinating dispersed R\&D activities funded by the European Commission. Since then, seven editions of the FP have been launched, evolving towards increasing budgets, new participation models and wider research priorities.

Throughout the seven editions, the operative scheme of the FP has been characterised by several key aspects. Roediger-Schula and Barber (2006) remark that all projects are promoted by self-organised consortia, shaped by different kinds of partners and located in different nations (usually, consortia are integrated by firms, public research centres, universities and users). Moreover, supported projects have a limited duration and their R\&D activity is co-financed by grants coming from the European Commission and private funds coming from consortia partners. Evaluation and selection processes have been traditionally based on scientific excellence and relevant socio-economic aspects and carried out by independent experts in each technological area.

R\&D cooperation within the FP is characterised by some specific features, such as the participation of universities and research institutes in consortia and the relevance of pre-competitive research. Thus, we can assume that FP projects are close to the public-private or institutional cooperation model. In fact, as we will show below, literature on FP impact remarks that the main contribution of this programme is the improvement of innovation capabilities and most of the empirical studies do not find a direct effect on economic results. 
Impact studies carried out in several European countries (the UK, Austria, Finland, Germany, and Ireland) have reported the same general conclusions regarding firms' performance: low levels of commercialisation, significant generation of new scientific knowledge, significant acquisition of technical knowledge and capabilities; improved access to technical networks (DTI-Office of Science and Technology, 2004). In the same line, Georghiou et al. (1992) find that the main benefit for industry is the improvement of skills. Also Luukkonen (1998) observes that the promotion of 'infrastructural' matters (such as skills and training of personnel) can be considered the primary impact of EU research programmes.

The specifics of the FP regarding economic impact are reinforced by Benfratello and Sembenelli (2002). Matching data on 411 participants in Eureka and in the FP and balance sheet information from the AMADEUS database, these authors compare the effect of cooperation taking place in the two different programmes. They corroborate the positive influence of Eureka cooperation on some economic variables (labour productivity and price cost margins), but they cannot find any effect for the case of FP participants. Authors explain these results by the differences between the two programmes: Eureka is more market-oriented and the FP is more focused on pre-competitive projects.

Some studies have found different effects regarding firms' characteristics. Thus, Luukkonen (2000) suggests that commercial and short-term objectives are much more relevant for small firms, since these companies are not able to maintain a large project portfolio and their innovation activity is based on short return periods, allowing them to finance consecutive R\&D projects (European Commission, 2009). For the case of the Swedish industry, Arnold et al. (2008) report that the FP impact largely depends on the activity branch. They analyse four industries and confirm that, when the objectives of the FP consortia are closer to the market and the participation of big companies is more important, like in ICT or vehicles, the economic impact is higher. On the contrary, in live sciences or energy, the most relevant impact of the FP is related to the increasing technological capabilities of small and medium-sized firms (SME).

Similar results were obtained by Polt, Vonortas and Fisher (2008). They analyse the relationship between the participation in the FP and the innovative activity of enterprises using data from the Community Innovation Survey and a wide database on participation in FP5 and FP6. They remark that industrial participants are characterised by higher R\&D intensity and better 
network advantages. They are more oriented to international markets and have a greater propensity to patent. Compared with projects financed by other sources, FP projects are less market-oriented, have longer development periods, are focused on non-core technologies of participants and are related to basic research activities. From the organisation perspective, these authors find that FP projects must face a lower degree of flexibility and higher administrative burdens. According to this empirical evidence, the authors conclude that the participation of non-entrepreneurial organisations is increasing and, consequently, the proportion of results that could lead directly to industrial innovation has declined.

Introducing a new perspective, Dekker and Kleinknecht (2008) take into account the selfselection of applicants and analyse whether the FP participants from the Netherlands, Germany and France have better performance indicators because they participate or because they are more innovative. They confirm the existence of the self-selection bias associated with participation in the FP and estimate the impact equation correcting this aspect. Concerning the FP impact, they consider firms participating indistinctly in FP4 and FP5 and analyse the effect on innovative output, measured as logs of sales of innovative products per employee. These authors cannot corroborate a positive effect on innovative results, but they find a positive influence on R\&D intensity for companies with fewer than 100 employees.

To summarise, empirical evidence on the impact of the FP seems to indicate that the main contribution of this programme to the industry participants is related to the improvement of scientific and technological capabilities and not directly to the firms' economic performance.

\section{Empirical model and data}

With the objective of enlarging the scarce empirical evidence about the effects of R\&D cooperation on economic performance, our model turns to the literature on R\&D impact to find a suitable framework where technological output and economic efficiency interact. Following the seminal works by Solow (1957) and other authors which incorporated R\&D as an endogenous factor in the production function (Romer, 1990; Grossman and Helpman, 1991), many studies have tried to quantify the contribution of technology to the economic growth of a country, industry branch or enterprise, concluding that the private return of R\&D investments is lower than the social one. Griliches (1992), Mohnen (1996) and Nadiri (1993) confirmed 
that, on average, the social rate of return is $50 \%$ to $100 \%$ higher than the private one. Griliches and Mairesse (1984), Jaffe (1986) and Verspragen (1995) demonstrated that those spillover effects associated with $R \& D$ activities are responsible for the increasing rate of returns when knowledge flows from one firm or institution to others.

In the 1990s, available data on firms' innovative activities open new research paths and new approaches are proposed. One of the most relevant works is the paper by Crepón, Duguet and Mairesse (1998). Using data from the French Innovation Survey, these authors build a model (CDM model) which considers that the effect of R\&D on firms' productivity is the result of the innovation outputs and not directly of the R\&D activity. Their empirical analysis concludes that technological results are favoured by the R\&D intensity and the innovative dynamic of the activity branch. Moreover, productivity is positively influenced by the introduction of innovations in the market when controlling by human resources' qualification and physical capital.

The basic CDM model includes variables measuring the internal effort in R\&D, but does not take into account the effect of external spillovers. In this respect, cooperation has been considered by some authors a valid proxy for explaining knowledge generation associated with those knowledge spillovers. Cincera et al. (2003) argue that cooperation is an alternative for measuring voluntary access to external knowledge and also for controlling the involuntary outgoing spillovers. In fact, a considerable amount of empirical research corroborates the relationship between the propensity to cooperate and the relevance of spillovers for the innovation process (Cassiman and Veugelers, 2002; López, 2008; Abramovsky et al., 2009).

Our empirical approach, based on the CDM model, also establishes a recursive model structure to capture the relationship between $\mathrm{R} \& \mathrm{D}$ cooperation, knowledge generation and economic results. However, at the same time, we take into account that the participation in RJV supported by the EU FP implies a process selection that includes both the self-selection by participants to join the R\&D consortia and the selection of projects by the European Commission to award the public aid.

In this sense, when analysing the impact of any public aid, the implicit question to answer is what the behaviour of a supported firm would have been if it had not received this public aid. The problem is that each firm can only be observed either in the status of receiving the public 
support or not; that is, we cannot directly observe the additional effect. As is well known, if aid was granted randomly to firms (or consortia), we could estimate the effect of public aid on (for instance) performance as the difference between the average one in supported and nonsupported firms. However, the evidence shows that aid is not granted randomly. Therefore, to measure the effect of public aid, we need to estimate or approximate the counterfactual. That is, we have to take into account that the awarding decision by the public agency probably depends on the same firm (or consortia) characteristics that determine performance. The econometric literature has developed several methods in order to solve these difficulties ${ }^{2}$. One of the most used alternatives, and the one that will be followed here, is the Heckman selection model, which involves estimating what determines the receipt of the aid (the "selection equation").

Nevertheless, the application of this method is not free of difficulties. Most of the empirical studies that try to explain the impact of national or international aid programmes have information only about financed projects, and therefore are not able to distinguish between the firm's decision to apply for the aid and the agency selection among the proposals (see, for example, Blanes and Busom (2004), who refer to participation in R\&D subsidy programmes). The main disadvantage of this lack of information is that the selectivity problem is not fully considered. However, in our database, we also have data about rejected applications, so we can estimate separately the determinants of both decisions.

Therefore, our empirical model consists of four equations that reflect the following recursive stages: first, the firm's decision to apply for the aid; second, the agency selection among the proposals; third, the generation of knowledge from the innovation activities involved in the cooperative R\&D project; and, finally, the addition of this new knowledge to the production process.

Formally, the equation which describes the decision to apply for an FP cooperation project takes the form:

$$
y_{1 i}= \begin{cases}1 & \text { if } y_{1 i}^{*}=x_{1 i} \beta_{1}+u_{1 i}>0 \\ 0 & \text { otherwise }\end{cases}
$$

\footnotetext{
${ }^{2}$ See a detailed discussion of the different methods in the survey by Aerts, Czarnitzki and Fier (2007).
} 
where $y_{1 i}^{*}$ is a latent dependent variable, $x_{1 i}$ is the set of explanatory variables, $\beta_{1}$ is the vector of coefficients and $u_{l \mathrm{i}}$ is the error term. The firm $i$ applies within the FP if $y_{1 i}^{*}$ is positive.

Conditional on firm $i$ applying, the agency can award or reject the proposal. Again, the probability of being awarded is formalised in terms of a binary model:

$$
y_{2 i}= \begin{cases}1 & \text { if } y_{2 i}^{*}=x_{2 i} \beta_{2}+u_{2 i}>0 \\ 0 & \text { otherwise }\end{cases}
$$

where $y_{2 i}^{*}$ is the latent dependent variable, $\beta_{2}$ is the vector of coefficients, $u_{2 \mathrm{i}}$ is the error term, and $x_{2 i}$ is the set of explanatory variables which are assumed to be strictly exogenous or predetermined longer in advance. The proposal in which firm $i$ participates is approved if $y_{2 i}^{*}$ is positive. ${ }^{3}$

The error terms in equations (1) and (2) might contain some common omitted variables, and therefore the correlation term $\rho$ between $u_{1}$ and $u_{2}$ might be unequal to zero. In that case, there may be a sample selection bias, and the estimation of coefficients $\beta_{2}$ only for proposals yields inconsistent estimates. To face this problem, following Van de Ven and Van Praag (1981), we estimate both equations as a Probit model with sample selection by maximum likelihood, applying, in a Probit analysis, the same device that Heckman (1979) introduced for an analogous problem when explaining a non-dichotomous variable.

After the joint estimation of both equations, we proceed to estimate the impact of the supported cooperative project in terms of output. Given that the R\&D projects supported through the FP are generally long-term projects (the average duration of a project is around 24 months and before starting the project, the negotiation phase with the European Commission could also take several months), it seems reasonable to analyse its impact once the project has formally finished. This is even more justified in the case of consortia supported by the Framework Programme, as it is more focused on pre-competitive projects than other programmes supporting JVs, which are more market-oriented. To capture the expected long-term effects, the measures of output that we include in our analysis refer to the period $t+5$ relative to the awarding year.

\footnotetext{
${ }^{3}$ Notice that more than one firm can participate in the same proposal, and the same firm can participate in more than one proposal every year. To establish a clear correspondence between firms and projects, in our sample we have only included one project per firm and year.
} 
Specifically, in the second step, we analyse how participation of the firm in an FP project affects the generation of new knowledge. This is approached by the proportion of intangible fixed assets over employment, which constitutes an indirect measure of innovation output, given that the knowledge generated in the R\&D project will usually be reflected by the volume of intangibles inside the firm (especially in the case of patents and R\&D investments). Therefore, the next equation in our model is:

$$
k_{i}=\gamma p_{i}^{*}+x_{3 i} \beta_{3}+u_{3 i}
$$

, where $k_{i}$ stands for a firm's intangible fixed assets, and $p_{i}^{*}$ denotes the predicted value for the probability of participating within the FP. We include the prediction instead of the dummy for observed participation to take care of the selectivity problem. $x_{3 i}$ is a vector of other control variables in equation (3).

In the last step of the model, we estimated the impact of the intangible assets, as an indicator of knowledge capital, on a firm's labour productivity, as an indicator of economic success. Therefore, if we find that intangibles are affected by participation within the FP, and that these intangibles increase productivity, the economic impact of the cooperative project will also be supported by the evidence. As a consequence, the last equation in our model takes the form

$$
g_{i}=\pi k_{i}+x_{4 i} \beta_{4}+u_{4 i}
$$

, where $g_{i}$ is labour productivity, $k_{i}$ is knowledge capital (represented by intangible assets) and $x_{4 i}$ stands for other additional controls in equation (4). We take care of the endogeneity of $k_{i}$ in this equation by using the predicted values from equation (3) in the estimation.

In equations (3) and (4), dependent variables refer to period $t+5$ relative to the awarding year. As we have explained previously, the R\&D projects supported by the FP are generally longterm, and it seems reasonable to analyse its impact once they have formally finished and firms have obtained economic returns. ${ }^{4}$

To summarise, in this paper we apply a structural model which has the following basic structure: (i) firms decide whether or not to apply for a FP cooperation project; (ii) the proposal is

\footnotetext{
${ }^{4}$ In fact, in their analysis of the effectiveness of the Eureka Program, Bayona-Sáez and García-Marco (2010) find that the completion of a Eureka project has a positive impact over firms performance measured as return over assets, although the effect does not manifest itself until a year after project completion.
} 
awarded or rejected by the European Commission; (iii) the innovation activities involved in the cooperative $R \& D$ project succeed through the generation of new knowledge (represented by intangibles); (iv) the addition of this new knowledge to the production process results in productivity growth. Since we assume a recursive model structure and do not allow for feedback effects, we follow a three-step estimation procedure. In the first step, we estimate a maximum likelihood probit model with sample selection (equations (1) and (2)). In the second step, we estimate the knowledge production function (equation (3)) (proxied by the stock of intangible fixed assets), using the predicted value of the probability of participating within the FP to take care of the selectivity problem. In the last step, we estimate the productivity equation, using the proportion of intangible fixed assets as an indicator of knowledge generation.

We choose this structural model because it captures the main features of the phenomenon we want to analyse, but is parsimonious and empirically tractable with the data we have available.

\subsection{Database}

Empirical analysis is focused on consortia supported by EU FP and, more specifically, our sample refers to Spanish participants during the period 1995-2005. The database used here is provided by the Centre for the Development of Industrial Technology (CDTI), which is the public organisation in charge of monitoring the participation of Spanish firms within the FP. Since FP6 went into effect, the CDTI has been the organisation in charge of the maintenance and management of the information related to Spanish participation in the FP. As a consequence, the CDTI-PM database includes information about all the proposals, ${ }^{5}$ eventually granted or not, in which at least one Spanish firm participated between 1995 and 2005. This period covers part of FP4 (1994-1998), all of FP5 (1999-2002) and part of FP6 (2003-2006).

This information from the CDTI-PM database has been complemented with the SABI database that contains the company accounts of more than 1,000,000 Spanish firms between 1995 and 2007. The merger of the CDTI-PM and SABI databases has been possible because Spanish firms are identified both in the CDTI-PM and the SABI databases through their company tax codes.

\footnotetext{
${ }^{5}$ To guarantee the homogeneity of the sample, only Specific Targeted Research Projects (STREPs) and Integrated Projects are considered.
} 
From the SABI database, we have selected a control sample that takes into account the availability of data about the relevant variables for each firm. Given that Spanish firm size is smaller than the European average (European Commission, 2003), we have designed the sample selection considering a firm to be large when its number of workers exceeds 200, although the threshold in international statistics is usually set at 250 . We have chosen all companies employing more than 200 employees. Firms employing between 10 and 200 employees are selected by a random sampling scheme for each NACE class (two-digit) level, and represent around $4 \%$ of the Spanish Central Companies Directory (CCD), which comprises all Spanish companies and their local units. This makes our control sample representative of the Spanish economy. ${ }^{6}$ Although we have information since 1995, the sample used in the empirical analysis of participation refers only to the period 1999 to 2005, given that FP5 started in 1999 and we want to take into account experience, if any, in the previous programme. In addition, as we use the forward values of output measures to capture long-term relationships, in some estimates the number of years with complete information is reduced to 4 .

Since our objective is to analyse the impact of collaboration within the FP on performance variables, our unity of analysis is the firm. In this sense, although some firms have applied in more than one proposal every year, we only consider one project per firm and year. We have given priority to those supported projects with bigger subsidies. After that, 1,555 observations have been eliminated, where 142 observations refer to supported projects. We have also excluded observations of the extreme values of employment and sales growth rates. Specifically, we have eliminated values in the extreme percentiles ( 1 and 99\%). In addition, we dropped negative values for productivity, tangibles and intangible fixed assets. Overall, the final sample consists of an unbalanced panel of 56,945 observations, 11,435 companies, and 2,536 proposals.

The CDTI-PM database allows us to analyse specifically those factors related to agency selection $^{7}$, while the information from the joint database is used mainly to estimate the firm's decision to engage in a cooperative project, and the impact of participation on the firm's output.

\footnotetext{
${ }^{6}$ Coverage of the data is basically restricted to firms that have at least 10 employees (annual average), but we have also included 615 micro-companies $(0.5 \%$ of the $\mathrm{CCD}$, chosen again by means of a random sampling scheme), given that 219 applicants of cooperative FP projects belong to this category.

${ }^{7}$ Proposals are evaluated by independent experts according to some common criteria. However, such information is absent from our database.
} 


\section{Results}

In this section, we present the results of the estimation of the model depicted in Section 3. As equations (1) to (4) point out, we assume a recursive model where feedback from performance variables to the decision of applying for a FP cooperation project is not allowed. Taking this into account, we follow a three-stage estimation procedure. In the first stage, a probit model with sample selection including the decision to participate in a cooperative R\&D project within the FP and the decision of awarding by the EC are jointly estimated consistently by maximum likelihood. In the second stage, we estimate the generation of new knowledge (equation (3)), approaching the innovation output by the intangible fixed asset and introducing the predicted value of the probability of participating within the FP as an explanatory variable. In the last stage, the productivity growth equation (4) is estimated by including a proxy of the new knowledge as an explanatory variable; specifically, we introduce the predicted value of intangible fixed assets.

\subsection{Cooperation within the FP}

Tables 1 and 2 show the results of the joint estimation of equations (1) and (2) as a Probit model with sample selection by maximum likelihood, on the assumption that the error terms of both equations could be correlated. The first one exhibits the coefficients of the probit model for the firm's decision to apply for an FP cooperation project (equation (1)), while the second one corresponds to the probability of being awarded the subsidy by the EC (equation (2)). We also report marginal effects in square brackets. Notice that the correlation term $\rho$ in Table 2 is significant, pointing out the necessity of estimating a selection model for the awarding decision ${ }^{8}$.

The explanatory variables included in equations (1) and (2) follow the selection made by Barajas and Huergo (2010) for a quite similar sample ${ }^{9}$. The results basically confirm the evidence obtained in that paper. As for the applying equation, as can be seen in Table 1, most coefficients are statistically significant, although marginal effects are small except for those variables measuring the FP experience in the previous year. In general, explanatory variables

\footnotetext{
${ }^{8}$ The Heckman procedure for the binary response variable in STATA does not take into account the panel structure of the data and the information is treated as a pool. However, in Barajas and Huergo (2010), the decision to apply has been estimated as a random-effects probit model taking into account the panel structure of the data and the results are basically the same.

${ }^{9}$ Find the exact definitions of the variables in Appendix A.
} 
increase the probability of applying for an FP cooperation project, with the exception of the liquidity ratio, which has a negative impact, which is consistent with the idea that cooperation can be considered a strategy for avoiding financial obstacles associated with R\&D projects for firms with financial constraints.

Table 1: Probability of applying within the FP. Probit estimates.

\begin{tabular}{|c|c|c|c|c|}
\hline & \multicolumn{3}{|c|}{ Coefficient } & S. E. \\
\hline \multicolumn{5}{|l|}{ Time dummies } \\
\hline Year 2000 & -0.054 & & {$[-0.003]$} & 0.038 \\
\hline Year 2001 & -0.040 & & {$[-0.002]$} & 0.037 \\
\hline Year 2002 & -0.280 & $* * *$ & {$[-0.012]$} & 0.041 \\
\hline Year 2003 & 0.055 & & [0.003] & 0.036 \\
\hline Year 2004 & -0.258 & $* * *$ & {$[-0.011]$} & 0.040 \\
\hline Year 2005 & -0.233 & $* * *$ & {$[-0.010]$} & 0.041 \\
\hline Prior experience in FP proposals & 0.564 & $* * *$ & [0.047] & 0.029 \\
\hline Granted project in previous year & 1.545 & $* * *$ & [0.289] & 0.045 \\
\hline Rejected proposal in previous year & 1.650 & $* * *$ & [0.315] & 0.030 \\
\hline Exporter & 0.125 & $* * *$ & {$[0.006]$} & 0.023 \\
\hline Liquidity ratio & -0.048 & $* *$ & {$[-0.002]$} & 0.020 \\
\hline Intangible fixed assets over employment & 0.033 & $* * *$ & [0.002] & 0.008 \\
\hline EBITDA margin & 0.232 & $* * *$ & [0.012] & 0.087 \\
\hline Stock market & 0.322 & $* * *$ & {$[0.023]$} & 0.067 \\
\hline \multicolumn{5}{|l|}{ Firm's size dummies (no. of workers) } \\
\hline From 10 to 49 & -0.239 & $* * *$ & {$[-0.011]$} & 0.041 \\
\hline From 50 to 99 & -0.351 & $* * *$ & {$[-0.014]$} & 0.044 \\
\hline From 100 to 199 & -0.395 & $* * *$ & {$[-0.016]$} & 0.045 \\
\hline More than 200 & -0.385 & $* * *$ & {$[-0.018]$} & 0.040 \\
\hline \multicolumn{5}{|l|}{ High-tech services } \\
\hline Post and telecommunications & 0.603 & $* * *$ & [0.055] & 0.068 \\
\hline Computer and related activities & 0.459 & $* * *$ & {$[0.036]$} & 0.039 \\
\hline Research and development & 0.583 & $* * *$ & {$[0.053]$} & 0.072 \\
\hline \multicolumn{5}{|l|}{ High and medium-tech manufacturing } \\
\hline Chemicals and chemical products & 0.020 & & [0.001] & 0.049 \\
\hline Machinery and equipment n.e.c. & 0.020 & & {$[0.001]$} & 0.051 \\
\hline Office machinery and computers & 0.495 & $* * *$ & {$[0.041]$} & 0.144 \\
\hline Electrical machinery and apparatus n.e.c. & 0.052 & & {$[0.003]$} & 0.076 \\
\hline Radio, television and communication & 0.257 & $* * *$ & [0.017] & 0.076 \\
\hline Medical, precision and optical instruments & 0.156 & & [0.009] & 0.096 \\
\hline Motor vehicles, trailers and semi-trailers & 0.072 & & [0.004] & 0.073 \\
\hline Other transport equipment & 0.432 & $* * *$ & {$[0.034]$} & 0.079 \\
\hline Log of likelihood function & \multicolumn{4}{|c|}{$-8,190.55$} \\
\hline Number of observations & & & 56,945 & \\
\hline
\end{tabular}

Marginal effects in square brackets. S. E.: Estimated standard error. Coefficients significant at: $1 \%{ }^{* * *}, 5 \% * *, 10 \% *$. All regressions include the constant and regional dummies. Dummies excluded for firms with fewer than 10 employees and the year 1999. Marginal effects are computed at sample means. For dummy variables, the marginal effect corresponds to the change from 0 to 1 . 
Table 2: Probability of being awarded. Probit estimates.

\begin{tabular}{|c|c|c|c|c|}
\hline & \multicolumn{3}{|c|}{ Coefficient } & S. E. \\
\hline \multicolumn{5}{|l|}{ Year of the application } \\
\hline Year 2000 & 0.064 & & {$[0.007]$} & 0.114 \\
\hline Year 2001 & 0.241 & $* *$ & [0.029] & 0.109 \\
\hline Year 2002 & 0.149 & & {$[0.017]$} & 0.126 \\
\hline Year 2003 & -0.251 & & {$[-0.023]$} & 0.219 \\
\hline Year 2004 & 0.001 & & {$[0.000]$} & 0.217 \\
\hline Year 2005 & 0.016 & & {$[0.002]$} & 0.200 \\
\hline Participation of organisms & -0.470 & $* * *$ & {$[-0.050]$} & 0.168 \\
\hline Size (of consortium) & 0.707 & $* * *$ & [0.075] & 0.071 \\
\hline FP budget for the specific programme & -0.009 & & {$[-0.001]$} & 0.018 \\
\hline \multicolumn{5}{|l|}{ Leader nationality } \\
\hline British & -0.032 & & {$[-0.003]$} & 0.122 \\
\hline Dutch & 0.345 & * & [0.048] & 0.188 \\
\hline French & 0.220 & * & [0.028] & 0.127 \\
\hline German & 0.361 & $* * *$ & [0.051] & 0.113 \\
\hline Italian & -0.104 & & {$[-0.010]$} & 0.130 \\
\hline Spanish & 0.312 & *** & [0.042] & 0.087 \\
\hline \multicolumn{5}{|l|}{ Technological area } \\
\hline Aeronautic and aerospace & 0.259 & & [0.034] & 0.246 \\
\hline Agro-food & 0.261 & & [0.034] & 0.269 \\
\hline Environment and energy & 0.024 & & [0.003] & 0.230 \\
\hline ICT & 0.129 & & [0.015] & 0.217 \\
\hline Innovation programmes & 0.385 & & [0.055] & 0.335 \\
\hline New materials & 0.247 & & [0.032] & 0.195 \\
\hline Transports & 0.311 & ** & [0.042] & 0.130 \\
\hline Geographical distance & -1.079 & $* * *$ & {$[-0.114]$} & 0.107 \\
\hline Prior experience in granted FP projects & 0.143 & $*$ & {$[0.017]$} & 0.080 \\
\hline Granted project in previous year & -0.031 & & {$[-0.003]$} & 0.109 \\
\hline Rho & 0.089 & * & & 0.046 \\
\hline Log of likelihood function & \multicolumn{4}{|c|}{$-8,190.55$} \\
\hline Number of censored / uncensored obs & \multicolumn{4}{|c|}{$54,409 / 2,536$} \\
\hline
\end{tabular}

Marginal effects in square brackets. S. E.: Estimated standard error. Coefficients significant at: $1 \%{ }^{* * *}, 5 \% * *$, $10 \% *$. All regressions include the constant. Dummy excluded for the year 1999. Marginal effects are computed at sample means. For dummy variables, the marginal effect corresponds to the change from 0 to 1 .

When we analyse the coefficients of the time variables, we observe that firms applied in smaller proportion in 2002, 2004 and 2005. The first one corresponds to the last year of the edition of the FP5 and confirms that firms tend to submit a smaller percentage of proposals when the current programme edition is finishing, probably due to the lower number of calls for proposals. The other two dummy variables correspond to the FP6 and allow us to compare both FP5 and FP6. The results are consistent with the fact that, in comparison with FP5, FP6 
was less favourable to the technological objectives of Spanish firms ${ }^{10}$, which consequently applied in smaller proportions.

As expected, previous experience in FP proposals increases the probability of applying in future editions and especially when the prior experience took place during the previous year. Since the application process within the FP is very costly, companies in consortia that have been rejected will try to profit from the accumulated knowledge, applying to the following calls. The probability of engaging in an FP project increases about 30 points for firms with experience in the last year, while it increases almost five points for firms with experience in previous editions of the FP. In this sense, firms seem to follow a process of learning by doing in the application for FP projects.

With respect to the rest of the explanatory variables, exporters, firms that are on the stock market, and companies that present a higher ratio between intangible fixed assets and employment, are also more likely to apply ${ }^{11}$. The earnings in terms of sales (approached by EBITDA), as a measure of ex-ante firm market power, also present a positive effect. This result is coherent with the Schumpeterian hypothesis that the less competitive the markets are, the more incentives for firms to innovate (and to participate in R\&D consortia) since they are better able to capture innovation benefits. However, this empirical evidence could also be supporting the existence of an informal competitive process among proponents in order to take part in those FP consortia led by the most reputed organisation. Thus, the most profitable firms have a higher probability of being selected by consortia coordinators.

The coefficients of the set of size dummies indicate a negative impact of size on the probability of applying ${ }^{12}$. This unexpected result can be affected by the fact that our control sample is biased towards large firms, which are chosen on the basis of a census, while firms employing between 10 and 200 employees are selected by a random sampling scheme. Additional work would be necessary to study this result more closely ${ }^{13}$.

\footnotetext{
${ }^{10}$ The FP6 introduced new instruments, such as the Integrated Projects and the Networks of Excellence, giving priority to projects with more ambitious goals, longer development terms and bigger budgets.

${ }^{11}$ This evidence is consistent with Busom and Fernández-Ribas (2007), who find that the key characteristic of participants in European programs is the extent to which the firm operates in foreign markets, as measured by export intensity.

12 The results do not differ when the firm number of employees is included instead of the set of size dummies. The same happens in Tables 4 and 5.

${ }^{13}$ Barajas and Huergo (2010) present complementary estimations for two sub-samples: SME and large firms. They found a non-linear effect of size which is negative for the SME and positive for large firms.
} 
The last rows of Table 1 present the coefficients of industry dummies ${ }^{14}$. Firms that carry out high-tech activities are also more prone to become proponents. The probability of engaging in an FP project increases more than 5 points for companies in the Post and telecommunications service sector and R\&D sector. Also, affiliation to Computer and related activities, Office machinery and computers, and the transport equipment industry increases the probability of applying by about 4 points. ${ }^{15}$

Table 2 shows the coefficients corresponding to the estimation of the equation for the probability of being awarded aid by the EC. Again, the results confirm the evidence provided by Barajas and Huergo (2010). Firstly, the presence of public organisations within a consortium and the distance among the partners negatively affect the viability of the proposal. Both variables can be reflecting the existence of coordination costs. With respect to the participation of non-entrepreneurial organisations, these costs could be associated with the differences in private and public cooperation routines, especially concerning the protection of innovation results.

Secondly, the inclusion of a new member in the consortium increases the probability of being supported by 7.5 points. In this case, the required technological diversity of the research equipment seems to exceed the coordination cost associated with each additional partner.

Thirdly, the probability of being supported increases when the project belongs to the Transport area $^{16}$, and especially when the proposal is led by a German organisation. Spanish firms that participate in consortia led by companies or organisations from Germany - a very active country within the FP- probably earn greater experience, enjoy better coordination routines, and therefore are more likely to receive aid from the EC.

\footnotetext{
${ }^{14}$ We also include some other industry dummies with statistically significant effects. Specifically, Education, Clothing apparel and footwear and Other business activities, which include architectural and engineering activities and related technical consultancy, should be noted. An opposite case is the Hotels and restaurants industry, with a lower probability of participating in technological projects. In reference to the Energy sector, both FP4 and FP5 had specific programmes for the development of sustainable energies, which increased the occasions for firms to present proposals. The results are available from the authors upon request.

${ }^{15}$ As control variables we also consider a set of geographical dummies, given that the more technological Spanish firms tend to locate in specific regions. In particular firms located in the Basque Country, Catalonia, Madrid and Valencia show higher probabilities of submitting an application, which is consistent with the major concentration of technological firms in these regions.

${ }^{16}$ Most of the total budget of the FPs is allocated to information and communication technologies. Therefore, it seems that the EU gives priority to these technological areas. Our result that only firms which carry out FP programmes in Transport show a greater probability of receiving aid can be a consequence of the criteria followed to eliminate the firms which have more than one project. Most of the dropped observations are projects belonging to ICT, Transport and Aeronautical technologies areas.
} 
Previous experience in FP projects has less impact on the probability of being supported than on the probability of applying. It seems clear that "learning-by-doing" is a more relevant factor in explaining the decision to participate due to the complexity of the FP procedures and the need to exploit scope economies once the effort to apply is made and the consortium is shaped.

Finally, although the temporal dummies which indicate the year in which the firm applied are jointly significant, they do not present significant coefficients in any year. That is, according to these results, there are no specific differences in the probability of being supported in both FP5 and FP6.

\subsection{Impact on knowledge accumulation}

We next proceed to estimate equation (3). As already stated, to capture the impact of supported cooperative projects, our measure of technological output is the proportion of intangible fixed assets over employment. We assume that this constitutes an indirect measure of innovation output, given that the knowledge generated in the R\&D project will usually be reflected by the volume of intangibles inside the firm, especially if the new knowledge is protected through patents ${ }^{17}$. In Table 3, we describe the variables used in the following econometric analysis.

The firms' technological capabilities are represented by their intangible fixed assets, given the intangible character of $\mathrm{R} \& \mathrm{D}^{18}$. The difference of means test confirms that the average of this variable in the sample is higher for participants within the FP than for non-participants. The proportion of intangibles over employment is slightly lower for participants. On the contrary, the percentage of tangible fixed assets per employee is higher for supported firms. Participants seem to be more productive, although the difference is small.

We also take into account whether the firm's activity corresponds to a high-tech service sector or a high or medium-tech manufacturing sector according to the OCDE classification. The

\footnotetext{
${ }^{17}$ Most previous empirical evidence approaches technological inputs by R\&D expenditures and new knowledge by product and process innovations, or sales generated by new products. However, this information is not available in our database.

${ }^{18}$ Spanish accounting rules allow for the capitalisation of R\&D expenditures under certain conditions (mainly when there are reasonable expectations of marketable results).
} 
frequencies in Table 3 reflect a high presence of these activities among participants, especially in high-tech services.

Table 3: Features of the participants. Descriptive statistics

\begin{tabular}{|l|c|c|c|}
\hline Means of quantitative variables: & Total sample & Participants & Non-participants \\
\hline Intangible Fixed Assets $(€)$ & $3,120.05$ & $7,362.01$ & $3,091.83$ \\
Intangible Fixed Assets over Employment $(€)$ & 13.93 & 11.91 & 13.94 \\
Tangible Fixed Assets $(€)$ & $22,272.04$ & $108,593.5$ & $21,697.33$ \\
Tangible Fixed Assets over Employment $(€)$ & 76.49 & 127.38 & 76.15 \\
Productivity (sales over employment) $(€)$ & 247.17 & 268.77 & 247.02 \\
Firm size (no of employees) & 355.41 & 877.41 & 351.93 \\
\hline Frequencies of binary variables: & Total sample & Participants & Non-participants \\
\hline Stock market & 1.25 & 6.87 & 1.21 \\
Exporter & 49.81 & 66.76 & 49.70 \\
High and medium-tech manufacturing & 17.07 & 25.55 & 17.01 \\
High-tech services & 5.88 & 15.66 & 5.82 \\
\hline
\end{tabular}

A firm's export activity is captured through a binary variable that takes the value one if the firm is an exporter during the period. As we can see in Table 3, the percentage of exporters among participants is 16 points higher than among non-applicants.

As an additional control variable, we include a dichotomy variable that reflects whether the firm is listed on the stock market. This kind of company is usually financially more consolidated and international funds could be less attractive to it. However, firms on the stock market tend to show more formalised quality procedures and therefore could have more systematic collaboration routines. In our sample, stock market companies are more frequent among participants.

The empirical results are reported in Table 4. We assume that all explanatory variables are strictly exogenous and the estimation is carried out by OLS using a random effect model for panel data. We have included some control variables in the specification like time, size, export activity, industries (to capture some sector-specific effects as technological opportunities) and regional (to control for the concentration effect in some Spanish areas) dummies.

The coefficients reported in this table are semi-elasticities because the dependent variable is measured in logarithms. Specifically, as all explanatory variables are dummies, they show the 
variation rate in unitary terms of intangible fixed assets per employee when the explanatory variable changes from 0 to 1 .

Table 4: Intangible fixed assets per employee $(t+5)$

\begin{tabular}{|c|c|c|c|c|c|c|}
\hline & \multicolumn{3}{|c|}{ (1) } & \multicolumn{3}{|c|}{ (2) } \\
\hline & \multicolumn{2}{|c|}{ Coefficient } & S. E. & \multicolumn{2}{|c|}{ Coefficient } & S. E. \\
\hline FP participant (observed) & 0.083 & & 0.061 & & & \\
\hline FP participant (predicted) & & & & 0.394 & $* *$ & 0.172 \\
\hline Stock market & 1.174 & *** & 0.182 & 1.169 & $* * *$ & 0.181 \\
\hline Exporter & 0.156 & *** & 0.030 & 0.154 & *** & 0.030 \\
\hline \multicolumn{7}{|l|}{ Firm size dummies ( $\mathrm{n}^{\circ}$. of workers) } \\
\hline From 10 to 49 & -0.104 & ** & 0.048 & -0.104 & ** & 0.048 \\
\hline From 50 to 99 & -0.201 & *** & 0.052 & -0.201 & *** & 0.052 \\
\hline From 100 to 199 & -0.279 & *** & 0.053 & -0.280 & *** & 0.053 \\
\hline More than 200 & -0.358 & *** & 0.053 & -0.358 & *** & 0.053 \\
\hline High and medium-tech manufacturing & 0.073 & $* * *$ & 0.041 & 0.072 & * & 0.041 \\
\hline High-tech services & 0.318 & **** & 0.070 & 0.314 & $* * *$ & 0.070 \\
\hline Sigma of $\mathrm{u}$ & \multicolumn{3}{|c|}{1.210} & \multicolumn{3}{|c|}{1.209} \\
\hline Rho & \multicolumn{3}{|c|}{0.868} & \multicolumn{3}{|c|}{0.867} \\
\hline Number of observations & \multicolumn{3}{|c|}{23,089} & \multicolumn{3}{|c|}{23,089} \\
\hline
\end{tabular}

S. E.: Estimated standard error. Coefficients significant at: $1 \%{ }^{* * *}, 5 \% * *, 10 \% *$. All regressions include the constant, and regional and temporal dummies. Dummy excluded for firms with fewer than 10 workers.

Due to the pre-competitive orientation of FP projects, we assume that their results will have effects in the long term. In this sense, our dependent variable refers to the period $t+5$, where $t$ is the awarding year. In fact, when we consider periods $(t+3)$ and $(t+4)$, we do not find any significant effect of the participation in FP projects on intangible fixed assets. This is consistence with previous evidence which tries to capture these relationships in shorter periods (see, for example, Benfratello and Sembenelli, 2002, and Dekker and Kleinknecht, 2008). ${ }^{19}$

We are interested in comparing the effect of predicted participation versus observed participation. In Table 4, the first column corresponds to the model in which we included the dummy for observed participation (yes /no) as an explanatory variable, while in column (2), this variable is substituted by the prediction obtained in the previous step (estimations of equations (1) and (2)). It should be remarked that taking the selection problem into account is relevant: whereas the coefficient for observed participation is not significant, the predicted probability

\footnotetext{
${ }^{19}$ When we try the larger period $(t+6)$, the number of observations is reduced significantly and it is more difficult to capture robust effects. However, knowledge generated in previous periods is still a positive determinant of labour productivity in $(t+6)$.
} 
of participation positively affects our technological output. Specifically, being a firm that cooperates in an FP increases the ratio of intangible fixed active over employment almost $40 \%$. This result is in concordance with those presented by Dekker et al (2008).

With respect to the control variables, industry dummies are highly significant. Firms belonging to high-tech manufacturing and services and medium-tech manufacturing have a higher potential of generating technological outputs. The level of intangible fixed assets per employee increases $7 \%$ in manufacturing and more than $31 \%$ in services.

We obtain a negative effect of the size dummies. Most previous empirical evidence for Spanish manufacturing provides a positive relationship between firm size and the probability of being engaged in technological activities and obtaining product or process innovations, stressing the capacity of large firms to exploit economies of scale. However, a negative relationship is found in terms of innovation intensity: large firms present a lower proportion of resources in $\mathrm{R} \& \mathrm{D}$ with respect to smaller firms.

Finally, being a company listed on the stock market or being an exporter also positively affects the generation of new knowledge. Specifically, firms operating in international markets register an increment of $15 \%$ in the ratio of intangible fixed assets over employment.

\subsection{Impact on labour productivity}

The variable used to analyse the impact of cooperation on economic performance is labour productivity, measured as the ratio between total sales and number of employees. Estimations of the productivity equation (4) are shown in Table 5. Again, the estimation is carried out by OLS using a random effect model for panel data.

The coefficients reported in Table 5 are elasticities or semi-elasticities, since the dependent variable is the logarithms of sales per employee. In addition to control variables referring to size, industry, year, and firm location, we have included a proxy of physical capital intensity in the model, measured throughout the variable "tangible fixed asset per employee". Finally, to capture the effect of knowledge accumulation on productivity, we have included the predicted value of "intangible fixed assets over employment" from equation (3). 
By means of these estimations, we analyse whether participation within the FP has not only an indirect effect but also a direct effect on firms' economic success. As we have demonstrated in the previous section, the predicted probability of being awarded aid enhances the ratio of intangible fixed assets. If we find a positive relationship between this proxy of technological output and the level of productivity, the indirect economic impact of cooperation on productivity would be confirmed. If we find that FP participation also has a significant effect on productivity, an additional direct effect of cooperation on economic performance would be corroborated.

In the first column of Table 5, we present the obtained results, considering neither the observed nor the predicted participation to be explanatory variables. Under these conditions, the impact of the predicted value of "intangible fixed assets per employee" on productivity is clearly significant, reflecting a difference in favor of innovative firms. Specifically, if the ratio of intangible assets duplicates, it causes productivity to grow more than $12 \%$ (see Table 5). As firms participating in FP present higher technological outputs, this result supports an indirect effect of cooperation on this performance variable.

Table 5: Labour productivity $(\mathbf{t}+5)$

\begin{tabular}{|c|c|c|c|c|c|c|}
\hline & \multicolumn{2}{|l|}{ (1) } & \multicolumn{2}{|l|}{ (2) } & \multicolumn{2}{|c|}{ (3) } \\
\hline & Coefficient & S. E. & Coefficient & S.E. & Coefficient & S. E. \\
\hline FP participant (observed) & & & 0.010 & 0.032 & & \\
\hline FP participant (predicted) & & & & & 0.044 & 0.070 \\
\hline $\begin{array}{l}\text { Intangible Fixed Assets per employee } \\
\text { (predicted) }(\mathrm{t}+5)\end{array}$ & $0.121 * * *$ & 0.009 & $0.120 * * *$ & 0.012 & $0.120 * * *$ & 0.012 \\
\hline Tangible Fixed Assets per employee $(t+5)$ & $0.336 * * *$ & 0.005 & $0.336 * * *$ & 0.014 & $0.336 * * *$ & 0.014 \\
\hline Stock market & -0.110 & 0.089 & -0.111 & 0.168 & -0.111 & 0.168 \\
\hline Exporter & $0.381 * * *$ & 0.022 & $0.381 * * *$ & 0.025 & $0.381 * * *$ & 0.025 \\
\hline \multicolumn{7}{|l|}{ Firm size dummies ( $\mathrm{n}^{\circ}$ of workers) } \\
\hline From 10 to 49 & $0.079 * * *$ & 0.024 & $0.079 * *$ & 0.036 & $0.079 * *$ & 0.036 \\
\hline From 50 to 99 & $0.097 * * *$ & 0.027 & $0.097 * *$ & 0.038 & $0.097 * *$ & 0.038 \\
\hline From 100 to 199 & $0.122 * * *$ & 0.028 & $0.122 * * *$ & 0.039 & $0.122 * * *$ & 0.039 \\
\hline More than 200 & $0.130 * * *$ & 0.028 & $0.130 * * *$ & 0.039 & $0.130 * * *$ & 0.039 \\
\hline High and medium-tech manufacturing & $0.152 * * *$ & 0.029 & $0.152 * * *$ & 0.028 & $0.152 * * *$ & 0.028 \\
\hline High-tech services & $-0.094 * *$ & 0.047 & $-0.094 * *$ & 0.046 & $-0.094 * *$ & 0.046 \\
\hline Sigma of $\mathrm{u}$ & \multicolumn{2}{|c|}{0.889} & \multicolumn{2}{|l|}{0.889} & \multicolumn{2}{|c|}{0.889} \\
\hline Rho & \multicolumn{2}{|c|}{0.894} & \multicolumn{2}{|c|}{0.894} & \multicolumn{2}{|c|}{0.894} \\
\hline Number of observations & \multicolumn{2}{|c|}{22,985} & \multicolumn{2}{|c|}{22,985} & \multicolumn{2}{|c|}{22,985} \\
\hline
\end{tabular}

S. E.: Estimated standard error. Coefficients significant at: 1\%***, 5\%**, 10\%*. All regressions include the constant, and regional and temporal dummies. Dummy excluded for firms with less than 10 workers. 
In columns (2) and (3), the specification also includes the dummy for observed and predicted participation, respectively. As can be seen, both of them are not significant. Therefore, it seems that cooperation in FP does not have a direct effect on performance variables. This result is in concordance with those presented by Benfratello and Sembenelli (2002). Using a different methodology, they do not find significant differences in the labour productivity of firms that have participated in FP 3 and FP 4. In a similar way, Dekker et al (2008) confirm that innovative output - sales of innovative product per employee- is not enhanced by participation in the EU FP in France, Germany and The Netherlands.

Additionally, there are no changes in the coefficients of the rest of variables. Capital- intensive firms - approached by the ratio "tangible fixed assets per employee" - are also more productive. As in previous empirical evidence, exporting firms are also more efficient than nonexporting firms.

With respect to the size dummies, we find a positive linear relationship between firm size and productivity. As expected, we also obtain that firms from high-tech and medium-tech manufacturing industries present larger levels of productivity. However, the opposite happens with firms in high-tech services.

Finally, as a robustness check we estimate the model using the growth rate of labour productivity as a dependent variable in equation $(4)^{20}$. In this case, intangible fixed assets per employee are also included in growth rates in equation (3). The results confirm the positive impact of cooperation within the FP on the technological capacity of firms and the indirect effect of participating in the FP on labour productivity through intangible fixed assets. We have also tested whether our results are robust to other measures of economic performance that are available in our database and that should indirectly capture improvements in the firm's efficiency or market share associated with the generation of new knowledge. Specifically, we consider the firm sales and ETBIDA ${ }^{21}$. The results confirm those obtained with labour productivity.

\footnotetext{
${ }^{20}$ See the results of the estimates for equations (3) and (4) in Tables B.1 and B.2 of Appendix B.

${ }^{21}$ See Table B.3 of Appendix B.
} 


\section{Conclusions}

The objective of this paper is to analyse the effects of $R \& D$ cooperation on economic performance. Empirical analysis is focused on RJV supported by the R\&D Framework Programme (FP) of the European Union and, more specifically, on Spanish firms participating during the period 1995-2005.

Although the average annual budget of the FP represents scarcely $4 \%$ of the total public funds devoted to R\&D in European countries, this programme is considered the core instrument of EU technological policy. The FP contributes to meeting the goals of the Lisbon strategy and the European Research Area (ERA) initiative by means of increasing private expenditure on $\mathrm{R} \& \mathrm{D}$ and cross-border transfer of knowledge from public institutions to firms.

Ex-post evaluation and monitoring reports assessing FP performance have been carried out periodically under the auspices of the European Commission, recognising that there has been little evaluation of the effects of the FP on economy-level competitiveness and, moreover, it is not possible to corroborate that knowledge generated in $R \& D$ consortia is transferred to the industry to any great extent (European Commission, 2009).

Previous empirical analyses agree about the positive effect of the cooperation carried out within the FP on variables related to technological capabilities (Georghiou et al., 1992; Luukkonen, 1998; Arnold et al., 2008; Polt, Vonortas and Fisher, 2008; Dekker and Kleinknecht, 2008), but evidence about the effect on economic performance is scarce. Considering the specific features of the FP (ambitious projects; consortia shaped by different types of organisations located in different countries; long-term periods; pre-competitive orientation in most of the cases), it is obvious that the economic effect of this kind of project should be analysed from a different perspective.

In this respect, one of the main contributions of the present paper is the application of a recursive model structure to capture the relationship between cooperation, knowledge generation and economic results. The model, which is an adaptation of the CDM model linking technological inputs and outputs to productivity, has the following basic structure: (i) firms decide whether or not to apply for a FP cooperation project; (ii) the proposal is awarded or rejected by the European Commission; (iii) the innovation activities involved in the cooperative R\&D 
project succeed through the generation of new knowledge (represented by intangibles); (iv) the addition of this new knowledge to the production process causes productivity growth.

We think that, throughout this integrated methodology, policy makers can receive feedback about the collaboration process as a whole: from the decision to apply to the economic impact of that participation. Overall, our results show that R\&D cooperation within the FP is considered by innovative firms to be a strategic option for improving their technological capabilities in the medium and long term. But, at the same time, firms perceive that cooperation in the FP is a resource-consuming activity. Cooperation entails significant costs that not all firms can afford.

In particular, our results confirm the evidence obtained in a previous paper by Barajas and Huergo (2010) about the determinants of applying in the FP and being awarded aid by the European Commission. Previous experience in FP proposals increases the probability of applying in future editions, suggesting that firms follow a process of learning by doing in the application for FP projects. Policy makers should take this fact into account and make a clear distinction between firms with previous experience in cooperative projects and other firms. The first group has already developed internal capabilities to participate in research consortia and need support mainly in reducing costs and risks associated with R\&D. Non-experienced firms also need support to deal with the process of previous learning and, therefore, will profit from public diffusion, information and training measures.

Going one step further, we have confirmed that the predicted probability of participating in the FP has a positive impact on firms' technological capabilities. Specifically, five years after the project is awarded aid, the ratio of intangible fixed assets over employment increases almost $40 \%$.

Regarding economic impact, the key idea supported by this study is that the effect of participation in R\&D consortia on firms' productivity is produced through the channel of improving their technological capabilities. In this respect, it is necessary to take into account that the evaluation criteria followed in the FP refers to scientific and technological excellence, coordination abilities of the consortium, European added value (in terms of critical mass of resources mobilised and contribution to Community policies) and potential for disseminating the knowledge and achieving innovations. Therefore, results must be assessed according to 
these criteria and from a long-term perspective, once the specific project is finished and the market dynamic has allowed firms to introduce innovations. From this perspective, we find that, if intangible fixed assets per employee duplicate, it causes productivity to grow more than $12 \%$ five years after awarding aid to the project. This confirms the effectiveness of RJV in promoting economic growth, one of the main objectives of European policy makers since the adoption of the Lisbon Agenda in 2000.

The empirical evidence obtained in this paper opens a new perspective to assess the economic impact of RJV. Nevertheless, limitations and future research lines should be outlined. The direct impact of this type of cooperative agreements seems to be related to the improvement in innovative capabilities that, to a large extent, are intangible assets, which are difficult to measure. Considering intangible assets introduced in accounting, our work finds that participation in R\&D consortia within the FP has a positive impact. Since accounting systems only reflect some intangible assets, such as capitalised R\&D expenditures, patents and software, the pending issue is how to capture the impact of other intangibles. At present, surveys and interviews seem to be the best option for complementing this information. Our knowledge about the economic impact of the FP, and about the economic impact of R\&D consortia in general, will improve as more research on the economic value of intangible assets is done. 


\section{References}

Abramovsky, L., Kremp, E., López, A., Schmidt, T. \& H. Simpson (2009). Understanding cooperative R\&D activity: evidence from four European countries, Economics of Innovation and New Technology 18(3), 243-265.

Aerts, K., Czarnitzki, D., \& A. Fier (2007). Evaluación econométrica de las políticas públicas de I+D: situación actual. In Heijs, J. \& Buesa, M. (Eds.), Cooperación en innovación en España y el papel de las ayudas públicas. (79-104). Instituto de Estudios Fiscales, Madrid.

Arnold, E., Åström, T., Boekholt, P., Brown, N., Good, B., Holmberg, R., Meijer, I. \& G. van der Veen, (2008). Impacts of the Framework Programme in Sweden. VINNOVA, Stockholm.

Aschhoff, B. \& T. Schmidt (2008), Empirical Evidence on the Success of R\&D CooperationHappy Together?, Review of Industrial Organization 33 (1), 41-62.

Barajas, A., \& E. Huergo (2010). International R\&D Cooperation within the EU Framework Programme: Empirical Evidence for Spanish Firms, Economics of Innovation and New Technology 19(1-2), 87-111.

Bayona-Sáez, C. \& T. García-Marco (2010). Assessing the effectiveness of the Eureka Program, Research Policy 39, 1375-1386.

Belderbos, R., Carree, M., Diederen, B., Lokshin, B. \& R. Veugelers (2004). Heterogeneity in R\&D cooperation strategies, International Journal of Industrial Organization 22, $1237-1263$.

Benfratello, L. \& A. Sembenelli (2002). Research joint ventures and firm level performance, Research Policy 31, 493-507.

Blanes, J.V. \& I. Busom (2004). Who participates in R\&D subsidy programs? The case of Spanish manufacturing firms, Research Policy 33, 1459-76.

Branstetter, L.G. \& M. Sakakibara (2002). When Do Research Consortia Work Well and Why? Evidence from Japanese Panel Data, American Economic Review 92(1), 143159.

Breschi, S. \& L. Cusmano (2006). Unveiling the texture of a European Research Area. Emergence of oligarchic networks under the EU Framework Programmes. In Caloghirou, Y; A. Constantelou \& N.S. Vonortas (eds.), Knowledge Flows in European Industry, Routledge, Oxon.

Busom, I. \& A. Fernández-Ribas (2007). Do R\&D programs of different government levels in the European Union? IEEE Proceedings, The Atlanta Conference on STI Policy 2007.

Caloghirou, Y. \& N.S. Vonortas (2004). RJVs in Europe: trends, performance, impacts. In Caloghirou, Y., N.S. Vonortas \& S. Ioannides (eds.), European Collaboration in Research and Development, Edward Elgar, Cheltenham, UK y Northampton, MA, USA.

Cassiman, B., \& R. Veugelers (2002). R\&D Cooperation and Spillovers: Some Empirical Evidence from Belgium, American Economic Review 92(4), 1169-1184.

Combs, K.L. \& A. Link (2003). Innovation Policy in Search of an Economic Foundation: The Case of Research Partnerships in the United States, Technology Analysis \& Strategic Management 15(2), 177-187. 
Crepon, B., Duguet, E., \& J. Mairesse (1998). Research, innovation and productivity: an econometric analysis at the firm level, Economics of Innovation and New Technology $7,115-158$.

Dekker, R. \& A.H. Kleinknecht (2008). The EU Framework Programs: Are they worth doing?, MPRA Paper, 8503. University of Munich.

DTI-Office of Science and Technology (2004). Targeted Review of Added Value Provided by International R\&D Programmes, London. http://www.berr.gov.uk/files/file14840.pdf

European Commission (2009). Evaluation of the Sixth Framework Programmes for Research and Technological Development. 2002-2006. Report of the Expert Group. http://ec.europa.eu/research/reports/2009/pdf/fp6_evaluation_final_report_en.pdf

European Commission (2003). SMEs in Europe 2003.

Faems, D., Van Looy, B. \& K. Debackere (2005). The role of interorganizational collaboration within innovation strategies: towards a portfolio approach, Journal of Product Innovation Management 22(3), 238-250.

Georghiou, L. et al. (1992). The impact of EC policies for RTD upon S\&T in the UK, A report prepared for DGXII of the Commission of the European Communities and the UK Office of Science and Technology, by PREST, University of Manchester and SPRU, University of Sussex.

Griliches, Z. (1992). The search for R\&D spillovers, Scandinavian Journal of Economics 94, Supplement, 29-47.

Griliches, Z. \& J. Mairesse (1984). Productivity and R\&D at the Firm level. In Z. Griliches (ed.), R\&D, Patents and Productivity, 339-74. Chicago University Press, Chicago.

Grossman, G. \& Helpman, E. (1991). Expanding Product Variety. In Innovation and Growth in the Global Economy, MIT Press, Cambridge.

Hagedoorn, J., Link, A.N. \& N.S. Vonortas (2000). Research Partnerships, Research Policy 29, 567-586.

Hall, B.H., Link, A.N. \& J. T. Scott (2001). Barriers Inhibiting Industry from Partnering with Universities: Evidence from the Advanced Technology Program, Journal of Technology Transfer 26(1), 87-98.

Heckman, J. J. (1979). Sample selection bias as a specification error, Econometrica 47, 153162.

Jaffe, A. (1986). Technological opportunity and spillovers of R\&D: Evidence from firms' patents, profits and market value, American Economic Review 76, 984-1001.

Lööf, H. \& A. Broström (2008). Does knowledge diffusion between university and Industry increase innovativeness?, Journal of Technology Transfer 33(1), 73-90

Lööf, H. \& A. Heshmati (2002). Knowledge capital and performance heterogeneity: a firmlevel innovation study, International Journal of Production Economics 76(1), 61-85.

López, A. (2008). Determinants for R\&D cooperation: Evidence from Spanish manufacturing firms, International Journal of Industrial Organisation 26(1), 113-136.

Luukkonen T. (1998). The difficulties in assessing the impact of EU framework programmes, Research Policy 27, 599-610. 
Luukkonen T. (2000). Additionality of EU Framework Programmes, Research Policy 29, 711-724.

Martin, S. (2003). The Evaluation of Strategic Research Partnerships, Technology Analysis \& Strategic Management 15(2), 159-176.

Mohnen, P. (1996). R\&D Externalities and Productivity Growth, STI Review, OECD 18, 3966.

Mowery, D., Oxley, J.E. \& B.S. Silverman (1998). Technological overlap and interfirm cooperation: implications for the resource-based view of the firm, Research Policy 27(5), 507-523.

Nadiri M.I. (1993). Innovations and technological spillovers, NBER Working Paper 4423, Cambridge, MA.

Polt, W., Vonortas, N. \& R. Fisher (2008). Innovation Impact, Final report to the European Commission, Brussels: DG Research.

Roediger-Schluga, T. \& M.J. Barber (2006). The structure of R\&D collaboration networks in the European Framework Programmes, UNU-Merit Working Paper Series 2006-36.

Romer, P. (1990). Endogenous Technical Change, Journal of Political Economy, 5 (2), S71S102.

Siebert, R. (1996). The Impact of Research Joint Ventures on Firm Performance: An Empirical Assessment, WZB Working Paper FS IV, 96 - 13

Scott, T.S. (2003). Absorptive Capacity and the Efficiency of Research Partnerships, Technology Analysis \& Strategic Management 15(2), 247-253.

Solow, R. (1957). Technical Change and the Aggregated Production Function, Review of Economics and Statistics 39, 312-20.

Tsakanikas, A. \& Y. Caloghirou (2004). RJV formation by European firms: strategic considerations. In Caloghirou, Y., N.S. Vonortas \& S. Ioannides (eds.), European Collaboration in Research and Development, Edward Elgar, Cheltenham, UK y Northampton, MA, USA.

Van de Ven, W.P.M.M. \& B.M.S. Van Praag (1981). The Demand for Deductibles in Private Health Insurance. A Probit Model with Sample Selection, Journal of Econometrics 17, 229-252.

Verspragen, B. (1995). R\&D and Productivity: A Broad Cross-Section Cross-Country Look, Journal of Productivity Analysis 6, 117-35.

Veugelers, R. (1998). Collaboration in R\&D: an assessment of theoretical and empirical findings, De Economist 146, 419-443. 


\section{Appendix A: Definition of variables}

\begin{tabular}{|c|c|}
\hline EBITDA & Earnings Before Interest, Taxes, Depreciation and Amortization \\
\hline EBITDA margin & EBITDA divided by sales. \\
\hline Exporter & Company exports during the period. \\
\hline Firm size & Firm's number of employees in the current year $(<10,10-49,50-99,100-199,200+)$ \\
\hline FP budget for the specific programme & Percentage of the total FP budget allocated to each specific programme. \\
\hline Geographical distance & $\begin{array}{l}\text { Percentage of partners from Northern Europe, Eastern Europe and non-European coun- } \\
\text { tries in the total number of partners. The percentage is multiplied by } 2 \text { or } 3 \text { if the part- } \\
\text { ners are, respectively, from } 2 \text { or } 3 \text { of the aforementioned geographical areas. }\end{array}$ \\
\hline Granted project in the previous year & $\begin{array}{l}\text { At least one of the Spanish firms involved in the consortium participated in a granted } \\
\text { project the previous year. }\end{array}$ \\
\hline High-tech services & Company belongs to the high-tech services (NACE2 codes $64,72,73$ ). \\
\hline High and medium-tech manufacturing & $\begin{array}{l}\text { Company belongs to any high or medium-tech manufacturing sectors (NACE2 codes } \\
24,29,30,31,32,33,34,35) \text {. }\end{array}$ \\
\hline Intangible fixed assets per employee & $\begin{array}{l}\text { Ratio between intangible fixed assets and total employment in the current year (in } \\
\text { logs.) }\end{array}$ \\
\hline Labour productivity & Sales per employee (in logs.) \\
\hline Leader nationality & The leader of the consortium is (British, Dutch, French, German, Italian, Spanish). \\
\hline Liquidity ratio & Shareholders' funds in non-current liabilities in the current year \\
\hline Participation of organisations & $\begin{array}{l}\text { Ratio between the number of non-entrepreneurial organisations and the total number of } \\
\text { consortium members in the proposal. }\end{array}$ \\
\hline Prior experience in FP proposals & The Spanish firm applied to the FP in the edition previous to the current one. \\
\hline Prior experience in FP granted projects & $\begin{array}{l}\text { At least one of the Spanish firms involved in the consortium participated in a coopera- } \\
\text { tive project financed during the FP edition previous to the current one. }\end{array}$ \\
\hline Rejected proposal in the previous year & $\begin{array}{l}\text { At least one of the Spanish firms involved in the consortium participated in a rejected } \\
\text { project during the previous year. }\end{array}$ \\
\hline Size of the consortium & $\begin{array}{l}\text { Total number of members (firms, public organisations or other institutions) in the con- } \\
\text { sortium (in logs). }\end{array}$ \\
\hline Stock market & Company is listed on the stock market. \\
\hline Tangible fixed assets per employee & Ratio between tangible fixed assets and total employment in the current year (in logs.) \\
\hline Technological area & $\begin{array}{l}\text { Project is related to (ICT, new materials, environment and energy, transport, agro-food, } \\
\text { aeronautic and aerospace, innovation programmes). }\end{array}$ \\
\hline
\end{tabular}




\section{Appendix B: Complementary estimates}

Table B.1: Growth of intangible fixed assets per employee $(t+5)$

\begin{tabular}{|l|cc|cc|}
\hline & \multicolumn{2}{|c|}{$(1)$} & \multicolumn{2}{c|}{$(2)$} \\
\cline { 2 - 5 } & Coefficient & S. E. & Coefficient & S. E. \\
\hline FP participant (observed) & 0.094 & 0.065 & & \\
FP participant (predicted) & & & $0.355 * *$ & 0.158 \\
Stock market & 0.037 & 0.042 & 0.034 & 0.042 \\
Exporter & -0.011 & 0.008 & -0.012 & 0.008 \\
Firm size dummies (n'. of workers) & & & & \\
From 10 to 49 & 0.040 & 0.028 & 0.041 & 0.028 \\
From 50 to 99 & 0.034 & 0.028 & 0.035 & 0.028 \\
From 100 to 199 & 0.022 & 0.027 & 0.022 & 0.027 \\
More than 200 & 0.023 & 0.027 & 0.023 & 0.027 \\
High and medium-tech manufacturing & -0.003 & 0.010 & -0.004 & 0.010 \\
High-tech services & $-0.033 *$ & 0.017 & $-0.036 * *$ & 0.018 \\
\hline Sigma of u & \multicolumn{2}{|c|}{0.027} & \multicolumn{2}{|c|}{0.029} \\
\hline Rho & \multicolumn{2}{|c|}{0.002} & \multicolumn{2}{|c|}{0.003} \\
\hline Number of observations & \multicolumn{2}{|c|}{22,277} & \multicolumn{2}{|c|}{22,277} \\
\hline
\end{tabular}

S. E.: Estimated standard error. Coefficients significant at: $1 \%^{* * *}, 5 \% * *, 10 \% *$. All regressions include the constant, and regional and temporal dummies. Dummy excluded for firms with fewer than 10 workers.

Table B.2: Labour productivity growth $(t+5)$

\begin{tabular}{|c|c|c|c|c|c|c|c|c|c|}
\hline & \multicolumn{3}{|c|}{ (1) } & \multicolumn{3}{|c|}{ (2) } & \multicolumn{3}{|c|}{ (3) } \\
\hline & \multicolumn{2}{|c|}{ Coefficient } & \multirow{2}{*}{ S. E. } & \multicolumn{2}{|c|}{ Coefficient } & \multirow{2}{*}{$\frac{\text { S. E. }}{0.037}$} & \multicolumn{2}{|c|}{ Coefficient } & \multirow[t]{2}{*}{ S. E. } \\
\hline FP participant (observed) & & & & -0.006 & & & & & \\
\hline FP participant (predicted) & & & & & & & -0.015 & & 0.080 \\
\hline $\begin{array}{l}\text { Growth of intangible fixed assets per } \\
\text { employee, predicted }(\mathrm{t}+5)\end{array}$ & 0.375 & $* * *$ & 0.113 & 0.381 & $* * *$ & 0.116 & 0.389 & $* * *$ & 0.144 \\
\hline $\begin{array}{l}\text { Growth of tangible fixed assets per } \\
\text { employee }(\mathrm{t}+5)\end{array}$ & 0.446 & $* * *$ & 0.026 & 0.446 & $* * *$ & 0.026 & 0.446 & $* * *$ & 0.026 \\
\hline Stock market & -0.081 & & 0.056 & -0.081 & & 0.056 & -0.081 & & 0.056 \\
\hline Exporter & 0.003 & & 0.007 & 0.003 & & 0.007 & 0.003 & & 0.007 \\
\hline Firm size dummies ( $\mathrm{n}^{\circ}$ of workers) & & & & & & & & & \\
\hline From 10 to 49 & 0.025 & & 0.030 & 0.025 & & 0.030 & 0.025 & & 0.030 \\
\hline From 50 to 99 & 0.024 & & 0.030 & 0.023 & & 0.030 & 0.023 & & 0.030 \\
\hline From 100 to 199 & 0.044 & & 0.029 & 0.043 & & 0.029 & 0.043 & & 0.029 \\
\hline More than 200 & 0.036 & & 0.029 & 0.035 & & 0.029 & 0.035 & & 0.029 \\
\hline High and medium-tech manufacturing & 0.014 & * & 0.008 & 0.014 & $*$ & 0.008 & 0.014 & $*$ & 0.008 \\
\hline High-tech services & 0.038 & $* *$ & 0.016 & 0.039 & $* *$ & 0.016 & 0.039 & $* *$ & 0.016 \\
\hline Sigma of $\mathrm{u}$ & \multicolumn{3}{|c|}{0.177} & \multicolumn{3}{|c|}{0.177} & \multicolumn{3}{|c|}{0.177} \\
\hline Rho & \multicolumn{3}{|c|}{0.168} & \multicolumn{3}{|c|}{0.168} & \multicolumn{3}{|c|}{0.168} \\
\hline Number of observations & \multicolumn{3}{|c|}{22,137} & \multicolumn{3}{|c|}{22,137} & \multicolumn{3}{|c|}{22,137} \\
\hline
\end{tabular}

S. E.: Estimated standard error. Coefficients significant at: 1\%***, 5\%**, 10\%*. All regressions include the constant and regional dummies. Dummy excluded for firms with fewer than 10 workers. 
Table B.3: ETBIDA (t+5) and Sales ( $(+5)$

\begin{tabular}{|c|c|c|c|c|c|c|c|c|c|c|c|c|c|c|}
\hline & \multicolumn{8}{|c|}{ ETBIDA $(t+5)$} & \multicolumn{6}{|c|}{ Sales $(t+5)$} \\
\hline & \multicolumn{2}{|l|}{ (1) } & \multicolumn{3}{|c|}{ (2) } & \multicolumn{3}{|c|}{ (3) } & \multicolumn{2}{|l|}{ (1) } & \multicolumn{2}{|c|}{$(2)$} & \multicolumn{2}{|l|}{ (3) } \\
\hline & Coefficient & S.E. & Coeffic & icient & S.E. & Coeffi & icient & S.E. & Coefficient & S.E. & Coefficient & S.E. & Coefficient & S. E. \\
\hline FP participant (observed) & & & -0.324 & & 0.187 & & & & & & -0.007 & 0.034 & & \\
\hline FP participant (predicted) & & & & & & -0.293 & & 0.345 & & & & & 0.092 & 0.089 \\
\hline $\begin{array}{l}\text { Intangible Fixed Assets per employee } \\
\text { (predicted) }(\mathrm{t}+5)\end{array}$ & $0.258 * * *$ & 0.026 & 0.259 & $* * *$ & 0.026 & 0.259 & $* * *$ & 0.024 & $0.171 * * *$ & 0.018 & $0.172 * * *$ & 0.018 & $0.170 * * *$ & 0.018 \\
\hline Tangible Fixed Assets per employee $(\mathrm{t}+5)$ & $0.348 * * *$ & 0.020 & 0.348 & $* * *$ & 0.020 & 0.348 & $* * *$ & 0.017 & $0.038 * * *$ & 0.014 & $0.038 * * *$ & 0.014 & $0.038 * * *$ & 0.014 \\
\hline Stock market & 0.192 & 0.333 & 0.201 & & 0.333 & 0.196 & & 0.227 & $0.985 * * *$ & 0.236 & $0.985 * * *$ & 0.237 & $0.984 * * *$ & 0.237 \\
\hline Exporter & $0.221 * * *$ & 0.059 & 0.222 & $* * *$ & 0.059 & 0.222 & $* * *$ & 0.057 & $0.513 * * *$ & 0.035 & $0.513 * * *$ & 0.035 & $0.513 * * *$ & 0.035 \\
\hline \multicolumn{15}{|l|}{ Firm size dummies ( $\mathrm{n}^{\circ}$ of workers) } \\
\hline From 10 to 49 & $0.859 * * *$ & 0.094 & 0.857 & $* * *$ & 0.094 & 0.858 & $* * *$ & 0.094 & $0.284 * * *$ & 0.046 & $0.284 * * *$ & 0.046 & $0.284 * * *$ & 0.046 \\
\hline From 50 to 99 & $1.398 * * *$ & 0.101 & 1.397 & $* * *$ & 0.101 & 1.398 & $* * *$ & 0.100 & $0.583 * * *$ & 0.049 & $0.583 * * *$ & 0.049 & $0.584 * * *$ & 0.049 \\
\hline From 100 to 199 & $1.966 * * *$ & 0.104 & 1.965 & $* * *$ & 0.104 & 1.966 & $* * *$ & 0.101 & $0.897 * * *$ & 0.051 & $0.897 * * *$ & 0.051 & $0.897 * * *$ & 0.051 \\
\hline More than 200 & $2.447 * * *$ & 0.104 & 2.447 & $* * *$ & 0.104 & 2.448 & $* * *$ & 0.099 & $1.126 * * *$ & 0.054 & $1.126 * * *$ & 0.054 & $1.126 * * *$ & 0.054 \\
\hline High and medium-tech manufacturing & -0.071 & 0.080 & -0.068 & & 0.079 & -0.069 & & 0.074 & -0.065 & 0.046 & -0.065 & 0.046 & -0.065 & 0.046 \\
\hline High-tech services & $-0.302 * * *$ & 0.138 & -0.298 & $* * *$ & 0.138 & -0.299 & $* * *$ & 0.122 & $-0.903 * * *$ & 0.078 & $-0.903 * * *$ & 0.078 & $-0.904 * * *$ & 0.078 \\
\hline Sigma of $\mathrm{u}$ & \multicolumn{2}{|l|}{2.143} & \multicolumn{3}{|c|}{2.142} & \multicolumn{3}{|c|}{2.143} & \multicolumn{2}{|l|}{1.188} & \multicolumn{2}{|c|}{1.188} & \multicolumn{2}{|l|}{1.187} \\
\hline Rho & \multicolumn{2}{|l|}{0.682} & \multirow{2}{*}{\multicolumn{3}{|c|}{$\frac{0.682}{23.072}$}} & \multicolumn{3}{|c|}{0.682} & \multicolumn{2}{|c|}{0.941} & \multicolumn{2}{|c|}{0.941} & \multicolumn{2}{|l|}{0.941} \\
\hline Number of observations & \multicolumn{2}{|l|}{23,072} & & & & \multicolumn{3}{|c|}{23,072} & \multicolumn{2}{|c|}{22,985} & \multicolumn{2}{|c|}{22,985} & \multicolumn{2}{|l|}{22,985} \\
\hline
\end{tabular}

S. E.: Estimated standard error. Coefficients significant at: $1 \% * * *, 5 \% * *, 10 \% *$. All regressions include the constant, and regional and temporal dummies. Dummy excluded for firms with less than 10 workers. 